Original Research Paper

\title{
Future Aspirations and Confidence: The Moderating Effect of High School Teacher Support for Latinx Students
}

\author{
${ }^{1}$ Dr. Rebeca Mireles-Rios, ${ }^{2}$ Odelia Simon, ${ }^{3}$ Shadi Roshandel and ${ }^{4}$ Patricia Martin \\ ${ }^{1}$ Gevirtz Graduate School of Education, University of California, Santa Barbara, United States \\ ${ }^{2}$ Gevirtz Graduate School of Education, University of California, Santa Babrara, United States \\ ${ }^{3}$ Teacher Education, California State University, East Bay, United States \\ ${ }^{4}$ Higher Education \& Organizational Change, University of California, Los Angeles, United States
}

Article history

Received: 22-06-2019

Revised: 06-08-2019

Accepted: 16-08-2019

Corresponding Author: Dr. Rebeca Mireles-Rios Gevirtz Graduate School of Education, University of California, Santa Barbara, United States

Email: rebeca.rios@ucsb.edu

\begin{abstract}
There is limited discussion in the field of education on the topic of Latinx students' higher educational goals and expectations. Even less attention has been paid to understanding students' beliefs in their ability to fulfill their educational goals. This research aims to understand why Latinx students, including those with high educational aspirations, have a lower likelihood of graduating high school and attending college compared to other ethnic groups. This quantitative study examined 504 Latinx high school students' ( $M=15.9$ years) educational aspirations, confidence that they could reach their goals and their perceptions of teacher support. Results indicated the amount of teacher support a student perceived changed how much their educational aspirations predicted their confidence to achieve those goals. Gender differences were found between the types of perceived teacher support Latinx students receive. This study suggests that research should closer examine how Latinx students perceive support and how such support contributes to their future higher educational aspirations and actual confidence that they can achieve their dreams.
\end{abstract}

Keywords: Latinx Education, Confidence, College Aspirations, Higher Education, Teacher Academic and Emotional Support

\section{Introduction}

Latinx students are the fastest growing ethnic population in American K-12 schools; however, they remain underrepresented in the population of individuals with a college degree (Krogstad, 2016; National Center for Educational Statistics (NCES, 2016). As defined by Garcia (2018) we use the gender neutral term Latinx to refer to people with ties to Mexico, South America, Latin America and parts of the Carribean. Although Latinx adolescents report high educational aspirations (Kao and Tienda, 1998; Mireles-Rios and Romo, 2014a), compared to adolescents from other ethnic groups, they tend to report low expectations of graduating from high school and even lower expectations of attending and graduating from college (Bohon et al., 2006; Zhang et al., 2011; McGlynn, 2015). Thus, it is imperative to examine factors associated with the development of Latinx high school students' college aspirations in order to understand how to best support such students in their academic trajectories.
While educational aspirations and expectations are conceptually similar, aspirations (hopes for the future) may tap into the social significance of attending college, while expectations reflect the more realistic prediction of future educational attainment (Bohon et al., 2006). Research suggests that adolescents whose educational aspirations exceed their expectations tend to come from low socioeconomic backgrounds (Boxer et al., 2011), raising questions as to whether their low expectations are associated with their limited access to quality schools that provide a range of educational opportunities, including experienced and caring teachers as well as a supportive academic environment (Valenzuela, 1999; Gándara and Contreras, 2009). Given that aspirations are thought to be the initial step in students' college-going process (Hossler and Gallagher, 1987; Klasik, 2012), more research is needed to understand how Latinx adolescents' aspirations are shaped by various factors in their lives, such as interaction with significant adults. Understanding perceptions of support from teachers is important as Stanton-Salazar (2001) argues that emotional connections 
with teachers are important to the process of educational resilience in Mexican American youth and positive teacher relationships and interactions have positive academic outcomes for high school students (Croninger and Lee, 2001). Specifically, it is important to understand how Latinx students' post-secondary educational aspirations are related to their perceptions of support from teachers (Taggart and Paschal, 2017) and how this support can bolster student confidence in their ability to achieve their aspirations, as teacher support has been demonstrated to have significant implications for high school students' academic development (Roshandel and Hudley, 2018).

The underrepresentation of Latinx students in higher educational contexts may be in part because their high schools lack the resources to provide them with the confidence that they belong and can succeed in such contexts. Research shows many high-achieving Latinx students are not encouraged by their high school teachers to pursue the four-year college track (Witenko et al., 2017), despite being qualified for admission to such colleges (Zalaquett and Lopez, 2006). Furthermore, Latinx students often do not have access to information about the four-year college application process and experience at their high schools (Contreras, 2011). For example, in a qualitative study examining the critical role teacher interactions play in terms of Latino youth staying in school, Katz (1999) pointed out the sensitivity of Latino students to teacher messages about their potential to succeed or fail. Thus, this study further suggests the need to better understand how teachers may influence students' confidence that they can achieve their goals.

Bandura (1997) suggests that people are more likely to successfully perform an intended behavior if they have confidence in their ability to complete the task. Individuals who believe they can overcome potential obstacles, develop a sense of self-efficacy, or judgment of confidence, which empowers them to face challenges competently and influences the choices they are likely to make. Given this connection between motivation and actual behavior, in order for an aspiration to become a reality, there needs to be some level of confidence that the aspiration can materialize. Contending that expectations are linked to confidence underlines the importance of examining how confidence drives students' pursuits and beliefs in their college-going identities. Considering, the relationship between aspirations and confidence and the limited findings on how support and resources for pursuing higher education contribute to the incongruence between Latinx students' educational aspirations and expectations, it is crucial to determine whether interpersonal support from institutional agents, such as teachers, can address this inconsistency. The present study seeks to examine the following research question: Can teacher support alter the preexisting relationship between student aspirations and their confidence in achieving their goals?

\section{Teacher Support}

Teachers have the power to play a monumental role in building adolescents' confidence. For example, teachers can foster confidence in students by serving as role models and imparting their own academic experiences and stories of success and strife with their students. In a study by Martinez and Castellanos (2018) that examined male Latinx middle school students' career aspirations, the researchers found that students who were more engaged in school activities had greater opportunity to develop relationships with teachers who shared their own academic experiences with students, helping the students to carve out their own college trajectories. This finding supports prior research which argues that aspirations to attend college are not solely based on motivation, but can also be driven by school context and relationships with teachers, which can give students the confidence they need to make their aspirations a reality (Flores-Gonzalez, 2002; Gutman and Akerman, 2008; Martinez and Castellanos, 2018).

Research also consistently finds a positive relationship between teacher support and a myriad of advantageous outcomes, such as academic achievement, motivational outcomes, and educational aspirations (Wentzel, 1997; 1998; Davis, 2013; Wentzel et al., 2016; Roshandel and Hudley, 2018). This research also shows that better (e.g. stronger and more positive) teacherstudent relationships can help reduce the achievement gap (Gehlbach et al., 2016). In a classroom experimental design with Latinx and White middle school students, Bowen et al. (2013) found that when students were given a self-affirming writing prompt, their self-confidence in their own experiences and opinions increased. Together, these studies demonstrate that instruction and teacher communication can improve students' self-efficacy and confidence in their abilities.

Stanton-Salazar $(2001 ; 2011)$ argues that emotional connections with teachers are fundamental for educational resilience, specifically amongst MexicanAmerican youth. Multiple studies have shown that middle school Latinx students display greater engagement in school when they believe their teachers care about and have high expectations of them (Brewster and Bowen, 2004; Garcia-Reid et al., 2005; Woolley and Grogan-Kaylor, 2006). Roshandel and Hudley (2018) found that perceived support from teachers impacted $10^{\text {th }}$ and $11^{\text {th }}$ grade students' academic achievement and beliefs about their potential to attend a four-year institution. Similarly, based on a sample of ninth and $10^{\text {th }}$ 
grade Latinx youth, Alfaro et al. (2006) found that academic support from teachers was associated with increased academic motivation for both males and females. Conversely, Valenzuela's (1999; 2010) work demonstrated that when teachers misunderstood the Latinx student population and lacked "authentic" care for their students, the valuable student-teacher relationship was undermined. It is evident that teacher support has a substantial impact on adolescents' academic motivation and achievement, including Latinx populations. Yet, more research is needed to understand the various types of perceived teacher support.

\section{Types of Perceived Teacher Supaport}

There are many modes of teacher support that are differentially related to academic outcomes, however, emotional teacher support is the most widely studied of these and has been shown to have a notable contribution to academic outcomes. For example, Magnuson et al. (2006) found that teacher-student relationships, specifically children's perceptions of teachers' willingness to support personal issues, were connected to higher academic achievement. In a longitudinal study conducted with a diverse sample of adolescents, Gregory and Weinstein (2004) found that when adolescents perceived their teachers as respectful, understanding, and fair, they had greater rates of growth in academic achievement. Latinx students' perceptions of being liked, respected, and valued by teachers also has a significant impact on their academic achievement (Ibañez et al., 2004; Sánchez et al., 2005; Wentzel et al., 2016). Within a sample of Mexican-American females in elementary school, Mireles-Rios and Romo (2010b) revealed that the more students perceived their teachers as caring about their education, the better their academic performance in math. Moreover, the students with higher grades in reading perceived their teachers as friendlier compared to those with lower grades (Mireles-Rios and Romo, 2010). In a more recent study, Roshandel and Hudley (2018) found that strong perceptions of emotional support from teachers was associated with a greater endorsement of potentially attending a four-year college for Latina students. Findings by Niehaus et al. (2016) suggests that support from teachers is the most powerful indicator of academic outcomes for Latinx students, showing a greater influence than support from peers and family and influencing academic outcomes such as high school graduation rates and attendance at postsecondary institutions. Taking these observations into consideration with Woolley and Grogan-Kaylor's (2006) conclusion that teacher support is the strongest predictor of positive attitudes toward school and academic performance among middle and high school students, these findings underscore the importance of teachers establishing and maintaining a classroom environment of care and trust for Latinx students. It is therefore essential to understand how support from teachers may help shape Latinx students' confidence to pursue higher education.

\section{Student Aspirations and Confidence}

Compared to academic achievement and motivation, considerably fewer studies have examined the link between teacher support and student aspirations; however, research that has examined this relationship points to the significant influence that teacher support can exert on students' ambition. In a large sample of predominately European American high school seniors, Wilson and Wilson (1992) asked students the lowest level of education they would be satisfied completing and assessed their perceptions of teacher support. Findings indicated that adolescents who aspired to higher levels of education perceived more teacher support compared to students with lower aspirations. Walkey et al. (2013) study of a sample of high school students from New Zealand found that those with higher educational aspirations had a stronger personal relationship with their teachers compared to students with lower aspirations. The researchers suggest that, generally, students with lower aspirations believe their teachers do not care about their learning. Roshandel and Hudley (2018) found that teachers play a role in adolescents' development of their future college-going self, as their higher education aspirations were related to the types of support received from their teachers.

Although scant attention has been paid to the topic of Latinx students' educational goals and expectations, even less has been paid to their confidence that they can reach their educational goals. This issue is vital to understanding why, even with high educational aspirations, Latinx students have a lower likelihood of high school graduation and college attendance than other ethnic groups (Bohon, et al., 2006; Fry, 2009; Kao and Tienda, 1998; Zhang et al., 2011). In addition, it is important to examine how perceptions of teacher support may differ based on individual differences such as gender and how these variations play a role in shaping future aspirations and confidence.

\section{Gender Differences}

Previous research illustrates the role that gender plays in students' academic development, engagement and future aspirations (Wei-Cheng and Bikos, 2000; Reynolds and Pemberton, 2001). For example, female students tend to have higher aspirations and relate more to their teachers than males (Goodenow, 1993) and females' aspirations are more strongly influenced by perceived teacher support than those of males 
(Kuperminc et al., 2008). Among a sample of third to sixth graders, Furrer and Skinner (2003) found that females felt significantly more connected to their teachers than male students, reporting that their teachers made them feel special and accepted. In addition, examining the consequences of support from teachers is important because Latinx males are less likely to enroll in and complete college than their female counterparts (Zarate and Burciaga, 2010; Nuñez and Kim, 2012). It is important to examine if and how teachers may contribute to this inequity.

In a longitudinal study of Latinx students going to college, Zarate and Gallimore (2005) found that, starting in Kindergarten, teachers rated females more favorably than males. Roshandel and Hudley (2018) found that high school adolescents' college-going possible selves differ by gender, with females who perceived their teachers as more supportive being more likely to aspire and expect to attend a four-year college compared to males. Research has also consistently shown that Latinx males are frequently misunderstood or mistreated by teachers and educators (Tellez and Estep, 1997; Conchas and Vigil, 2010; Halx and Ortiz, 2011; Rios, 2011; Huerta, 2015; Rios, 2017). Thus, given the underrepresentation of Latinx males in higher education (Saenz and Ponjuan, 2009), it is critical that we look at gender differences in the shaping of future aspirations for Latinx high school students and the ways in which teacher support is related to Latinx adolescents' hopes and dreams for their futures. In addition, there is a need to better understand how teachers treat and support the college aspirations of their Latinx students.

\section{The Present Study}

The aforementioned research suggests that interpersonal relationships with teachers are particularly influential for student academic achievement, motivation and aspirations. Yet little is known about the role teachers play in bolstering high school students' confidence in their ability to reach their higher educational goals. The general goal of the current study was to examine, through quantitative means, whether and what type of teacher support enhances Latinx students' confidence that they can achieve their educational goals. Specifically, this study sought to examine how 1.) teacher support may predict students' confidence that they can achieve their future educational aspirations, and 2.) examine the gender differences in perceived teacher support and future aspirations for Latinx adolescents. We hypothesized that if means of teacher support (i.e. displaying care for students and being responsive to students' academic needs) communicates direct and indirect messages that students are valued and worth their teacher's time and effort, students are more likely to feel efficacious and confident in themselves. Conversely, perceived lack of interest from teachers may send a message to students that they are academically incapable, potentially resulting in a belief that they cannot achieve higher education and consequently refrain from pursuing it.

These questions are especially relevant today as the rate of Latinx students attending college continues to increase, making it important to understand how aspirations and confidence may play a major role in Latinx students' process of deciding to pursue and persist in higher education.

\section{Method}

\section{Participants and Procedures}

Participants were 504 Latinx high school students from a single high school in Southern California. The sample was $51 \%$ female. Survey options included male, female, and other. Since so few selected other, those reponses were not included in the total sample above. Students were approximately equally distributed between ninth, $10^{\text {th }}, 11^{\text {th }}$ and $12^{\text {th }}$ grades, with slightly fewer students in each increasing grade level and an average age of 15.9 years old. School administrators conveyed that the majority of the students were Mexican-American. Students identified on the survey that they were Latina/o. Trained members of the research team administered a 15-minute survey to the participants during their second period class and each classroom had at least two research assistants present to ensure data was collected systematically. There was a $96 \%$ response rate for the survey.

\section{Measures}

\section{Aspirations and Confidence}

To measure adolescents' educational aspirations, participants were asked the following question: "How far do you want to get in school?" This question included the options of graduating from: high school, a two-year community college or technical/vocational program, a four-year college, or a graduate program. Participants' confidence in achieving their educational goals was measured by asking students: "How certain are you that you will reach your educational goal?" This was rated as a three-point Likert-type variable, ranging from "I have doubts" to "I'm somewhat certain" to "I'm very certain."

\section{Perceived Teacher Support}

Adolescents' perceptions of teacher support were assessed using the teacher subscale of the Child and Adolescent Social Support Scale (Malecki and Demaray, 2003) which measures four types of social support: emotional support (e.g., "My teachers care about me"), instrumental support (e.g., "My teachers explain things that I don't understand"), informational support (e.g., "My teachers make sure I have what I need for school") 
and appraisal support (e.g., "My teachers tell me how well I do on tasks"). The reliability and validity of the scale has been tested with both middle school and high school students from white and minority backgrounds (Maleckiand Demaray, 2002).

\section{Teacher Communication}

Adolescents' discussions with their teachers regarding college were measured with a single item, "My teachers talk to me about my future college options," on a four-point Likert scale ranging from 1= Strongly Disagree to 4 = Strongly Agree.

\section{Control Measures}

\section{Educational Value}

Adolescents' belief in the value of education was measured with a single item, "I have to do well in school if I want to be a success later in life," presented on a four-point Likert scale ranging from 1= Strongly Disagree to $4=$ Strongly Agree. This variable was included to account for students' personal perception of school's importance for their future.

\section{Parental Encouragement}

Adolescents were asked their perceptions of parental encouragement to go to college using a single item: "My parents/guardians have encouraged me to go to a fouryear university." This question was presented on a fourpoint Likert scale ranging from $1=$ Strongly Disagree to $4=$ Strongly Agree. This variable was included to control for family emphasis on and support for higher education, since previous research has found that communication with parents about the future was more significant for Latinx females' enrollment in a four-year college than for males (Loya et al., 2015).

\section{Family Obligation}

Adolescents' perceptions of family obligation were measured with a single item, "I have a lot of family responsibility that makes school hard," on a four-point Likert scale ranging from $1=$ Strongly Disagree to $4=$ Strongly Agree $(M=2.497, S E=0.045)$. This variable controls for family obligations that may either prevent students from achieving their full potential in school despite their own efforts or mitigate the student's ability to attend further education even if they desire to do so.

\section{Academic Achievement}

Adolescents' math $(M=2.138, S E=0.050)$ and English $(M=2.527, S E=0.055)$ grades were measured to assess academic achievement. Grades were coded on a scale from 0-4 $(F=0, D=1, C=2, B=3, A=4)$. Grades were considered important to include for three reasons: first, while educational goals may or may not be pragmatic, grades help determine the realistic feasibility of achieving them; second, students with higher grades may have higher goals and that difference should be accounted for and third, teacher support may vary depending on the academic needs of the student.

\section{Demographics}

Demographic characteristics were also included as controls. Age $(M=15.97, S D=0.054)$ was included with the understanding that as students get closer to graduation, their confidence that they can achieve their goals may change, along with their understanding of the feasibility of those goals. Parent education was included to control for both family educational background and emphasis and as a proxy for socio-economic status. Approximately equal numbers of students had parents who did and did not graduate high school. 41 students had parents who attended a two-year or technical college, 32 had parents who attended a four-year college and 18 had parents who attended graduate school.

\section{Analysis}

Our model predicts students' confidence by moderating their academic aspirations with latent variables for teacher support. Given the many various influences found in the literature on teacher support (Gregory and Weinstein, 2004; Ibañez et al., 2004; Sánchez et al., 2005; Wentzel et al., 2016), we considered it vital to integrate these into our model. However, as these different aspects of teacher support, including everything from emotional to appraisal support, are all indicators of the larger latent variable of teacher support we opted to utilize a factor analysis to determine the teacher support variable scores. A factor analysis measures a common latent factor by accounting for the correlations among multiple observed variables (Fabrigar et al., 1999). Utilizing a latent factor analysis approach was determined to be more informative than using these variables either individually, which would not indicate how their overall teacher support relates to the outcome, or as a composite score, which would not allow for the factoring in of individual variable weights or error, as does a factor analysis (Fabrigar et al., 1999).

Analyses of these latent variables included an exploratory factor analysis (EFA) and confirmatory factor analysis (CFA) to determine and confirm the factor structure, conducted with two sub-samples taken from the overall sample to examine the underlying factor structure of teacher support, one for the EFA and the other for CFA. Each sub-sample contained $50 \%$ of the overall sample $(N=$ 504). Since the focus of this paper is to compare gender groups, we tested for measurement invariance to ensure factors' equivalence across groups. This is another advantage of using a factor analysis. While a composite score would allow for only straightforward group comparisons, a factor analysis allows us to compare gender groups in terms of how the individual variables relate to the latent factor, allowing us to see whether they are inherently 
different (Sass, 2011). Once the teacher support latent factors were reliably established, we tested the complete moderation model. After determining the underlying factor structure, the whole sample was used in a regression analysis with moderation, including the covariates selected to help isolate the prediction value of teacher support from other kinds of support. All analyses were conducted using Mplus 8 software (Muthén and Muthén, 2017).

\section{Exploratory Factor Analysis (EFA)}

The EFA was conducted using one of the $50 \%$ split sub-samples. By estimating the EFA on one part of the sample and the CFA on the other, it decreases the chance of the model being misestimated due to outliers. Data were examined in SPSS (v. 21.0) for irregularities prior to estimation in Mplus. A weighted least squares (WLSMV) estimator was utilized in this analysis (Muthén, 1984; Muthén et al., 1997). A promax rotation, an oblique method, was selected due to correlation between factors (Costello and Osborne, 2005). The number of factors was decided based upon fit statistics and factor loadings. Fit indices were used to assess model fit, including the Root Mean Square Error of Approximation (RMSEA), the Comparative Fit Index (CFI), the TuckerLewis Index (TLI), the Standardized Root Mean Square Residual (SRMR) and the Chi-square test. Criteria of a good fit (Bentler, 1990; Brown, 2006; $\mathrm{Hu}$ and Bentler, 1999) include an RMSEA of less than 0.060, while an adequate fit is considered less than 0.080. A CFI and TLI have an adequate fit above 0.900 and a good fit above 0.950 , while the SRMR is considered an adequate fit below 0.100 and a good fit below 0.080 .

\section{Confirmatory Factor Analysis (CFA)}

A CFA was conducted using the other $50 \%$ sub-sample to confirm the EFA findings using WLSMV estimation. One randomly selected item for each factor was set at 1.000 to be used as the reference variable. However, the reported loadings in Table 2 are the standardized loadings, used for ease of interpretation. Modification indices were observed, as were fit indices. Based upon previous screening of the data, there were some concerns males and females may experience teacher support differently, so following the initial overall CFA, invariance was tested on the basis of gender. Fit was assessed using the same fit statistics as used in the EFA, with the exception of the SRMR, which was replaced with weighted root mean square residual (WRMR), unavailable in Mplus CFA due to the nature of the data as ordered categorical and for which a model is considered a "good" fit when less than 1.000 (Yu, 2002).

\section{Measurement Invariance}

Measurement invariance testing is a modeling step that statistically tests to see if two latent factors are measured the same across groups and is considered necessary when groups are suspected to be different due to the non-comparability of parameter estimates and factor means across groups should the construct be noninvariant (Vandenberg and Lance, 2000). Strong factorial invariance demands three types of invariance: (1.) configural invariance, where the same model is estimated for both groups but parameters are allowed to differ, testing whether the groups' factors are conceptually equivalent, (2.) metric invariance, where the unstandardized factor loadings hold equal between groups, testing whether the groups are measured on the same metric, and (3.) scalar invariance, where the unstandardized intercepts hold equal between groups, measuring whether the groups start at the same level. Should any of these levels fail to find invariance, the subsequent levels fail as well - a model can be configurally and metrically invariant while having scalar non-invariance, but a model that is configurally noninvariant is also noninvariant on a metric and scalar level (Sass, 2011).

Due to the categorical nature of the data, invariance is tested using the DIFFTEST function in Mplus 8 (Muthén and Muthén, 2017). Models are compared using both a chi-square difference test $\left(\Delta \chi^{2}\right)$ and change in the CFI fit index ( $\Delta$ CFI; Cheung and Rensvold, 2002). While a non-significant difference in the $\Delta \chi^{2}$ suggests there is no significant increase in model misfit (Cheung and Rensvold, 2002), allowing an assumption of invariance, we use the $\triangle \mathrm{CFI}$ as an additional measure, considering a change greater than 0.002 to indicate poorer fit (Cheung and Rensvold, 2002; Meade et al., 2008). This is done to account for any oversensitivity in the $\Delta \chi^{2}$ due to the large sample (Meade et al., 2008).

\section{Moderation Model}

The final analysis is a model using the latent teacher support variables to moderate the prediction of confidence by aspirations, controlled by student educational value, parent encouragement, family obligation, math and English grades, and the various demographic variables and is tested using the entire sample. Moderation is an interaction between variables. If the interaction variable is significant, then the moderator (teacher support) significantly impacts the relationship between the predictor (aspirations) and the outcome (confidence) (Marsh et al., 2013; Muthén, 2016). In order to demonstrate the impact of the moderation variables, the model was run both with and without moderation. These analyses were run in Mplus 8, which allows for interactions using latent variables (i.e., "xwith"; Muthén et al., 2016; Muthén and Muthén, 2017).

\section{Results}

The following are the results of the EFA, CFA and Moderation Model. All covariates were grand mean centered, allowing for ease of interpretation and results presented unstandardized (Table 1). 
Table 1: Variable descriptive

\begin{tabular}{|c|c|c|c|c|}
\hline \multirow[b]{2}{*}{ Variable } & \multicolumn{2}{|c|}{ Females } & \multicolumn{2}{|c|}{ Males } \\
\hline & M & $(S E)$ & M & $(S E)$ \\
\hline Confidence & 1.20 & $(0.04)$ & 1.33 & $(0.03)$ \\
\hline Aspirations & 1.75 & $(0.04)$ & 2.08 & $(0.04)$ \\
\hline \multicolumn{5}{|l|}{ My teachers: } \\
\hline Care about me & 2.93 & $(0.04)$ & 2.99 & $(0.04)$ \\
\hline Treat me fairly & 2.99 & $(0.04)$ & 3.13 & $(0.04)$ \\
\hline Appreciate me & 2.82 & $(0.04)$ & 2.86 & $(0.04)$ \\
\hline Really listen to what I have to say & 2.84 & $(0.04)$ & 2.89 & $(0.04)$ \\
\hline Tell me when I do a good job & 2.99 & $(0.04)$ & 3.02 & $(0.04)$ \\
\hline Give me encouragement & 2.86 & $(0.04)$ & 2.92 & $(0.04)$ \\
\hline Respect me & 3.08 & $(0.04)$ & 3.26 & $(0.04)$ \\
\hline Care about whether or not I come to school & 2.66 & $(0.05)$ & 2.72 & $(0.04)$ \\
\hline Make it okay to ask questions & 3.26 & $(0.04)$ & 3.34 & $(0.03)$ \\
\hline Help me solve problems by giving me information & 3.00 & $(0.04)$ & 3.07 & $(0.04)$ \\
\hline Take time to help me learn to do something well & 2.96 & $(0.04)$ & 3.00 & $(0.04)$ \\
\hline Show me how to do things & 3.12 & $(0.04)$ & 3.18 & $(0.03)$ \\
\hline Teacher discusses college & 2.69 & $(0.05)$ & 2.83 & $(0.05)$ \\
\hline Educational value & 3.59 & $(0.04)$ & 3.81 & $(0.02)$ \\
\hline Parental encouragement & 3.52 & $(0.04)$ & 3.65 & $(0.04)$ \\
\hline Family obligation & 2.45 & $(0.05)$ & 2.58 & $(0.05)$ \\
\hline Math grade & 2.03 & $(0.06)$ & 2.14 & $(0.06)$ \\
\hline English grade & 2.28 & $(0.07)$ & 2.54 & $(0.06)$ \\
\hline Age & 15.90 & $(0.06)$ & 15.98 & $(0.06)$ \\
\hline Parent education & 0.97 & $(0.06)$ & 0.80 & $(0.06)$ \\
\hline
\end{tabular}

\section{Factor Analysis}

\section{$E F A$}

In the exploratory factor analysis on teacher support, variables with a loading of under 0.30 were removed from the model. Overall fit was assessed based on the stated criteria of a well-fitted model (Bentler, 1990; Brown, 2006; Hu and Bentler, 1999). Table 1 presents fit statistics for a one-, two-, and three-factor solution. While the threefactor model statistically appears to be a better fit, all items are cross-loaded between factors, suggesting it is not the appropriate model. However, the two-factor model allows for each item to be loaded onto a single factor. The twofactor solution was a more appropriate fit for the data, with a CFI of 0.99 , a TLI of 0.98 , an SRMR of 0.03 and a chisquare of 120.57(43), $p<0.001$. The RMSEA of 0.07 qualified it as an adequate, if not good fit, resulting in the acceptance of the two-factor solution.

\section{$C F A$}

A confirmatory factor analysis was run using the two-factor solution. This model had an RMSEA of 0.078 (90\% CI: $0.06-0.08$ ), a CFI of 0.99 , a TLI of 0.98 , a WRMR of 0.88 and a chi-square of 149.61(53), $p<0.001$. All fit statistics suggested a good fit, apart from the RMSEA and chi-square test, which suggest an adequate fit. The split sub-sample was separated into males and females for invariance testing by gender. Males had an RMSEA of 0.09, (90\% CI: 0.08-0.10), a CFI of 0.98 , a TLI of 0.97 , a WRMR of 1.11 , and a chisquare of 223.68(53), $p<0.001$, suggesting an adequate fit of the model with the data. Females had an RMSEA of 0.06 (90\% CI: $0.05-0.07)$, a CFI of 0.99 , a TLI of 0.99 , a WRMR of 0.78 and a chi-square of 123.67(53), $p<0.001$, suggesting a good fit of the model with the data. Based on the nature of the questions, we labeled the two factors emotional teacher support, consisting of items such as "My teachers care about me," and "My teachers appreciate me," and academic teacher support, consisting of items such as "My teachers make it ok to ask questions and "My teachers show me how to do things.

Invariance testing found that while the configural model fit well $\left(\chi^{2}(108)=149.99(p<0.01)\right.$, RMSEA $=0.04(90 \%$ $\mathrm{CI}=.03-0.06), \mathrm{CFI}=0.99, \mathrm{TLI}=.99)$, suggesting the two genders were conceptually the same, the test of metric invariance failed $\left(\Delta \chi^{2}(18)=32.09(p<0.05), \Delta \mathrm{CFI}=0.004\right.$, RMSEA $=0.52$, CFI $=.99$, TLI $=0.99)$. The $\Delta \chi^{2}$ is significant and the $\Delta C F I$ is greater than 0.002 , suggesting that the two genders are measured on different metrics and should not be compared or estimated together. Therefore, the moderation model must be run separately for males and females. Running the model with the genders combined would result in biased and inaccurate results. Based on this conclusion, separate Cronbach's alphas were calculated for each gender (Males: academic teacher support $=0.89$, emotional teacher support $=0.93$; Females: academic teacher support $=0.88$, emotional teacher support $=0.91$ ).

Males and females can therefore be considered inherently different in how they perceive and experience teacher support, with different items, or aspects of teacher support, having slightly different weight for the two groups. However, the two factors have a similar relationship, with a correlation of 0.87 for males and 0.87 for females. As there are only two latent variables, estimation of any higher order factor was not possible 
despite the high correlation between them; Conceptually the two factors were considered distinct and thus not combined. Factor loadings for each item can be seen in Table 2 .

\section{Moderation Model}

Following completion of the CFA, the final model was tested. This model (presented in Fig. 1 and Table 3), suggests that teacher support moderates the relationship between student aspirations and confidence, and was run separately for males and females based on the finding of noninvariance by gender. By including the covariates of family encouragement to pursue a four-year college education, and students' own belief in the importance of education, we control for some of the outside influences on both their aspirations and expectations of achieving their goals, while the inclusion of grades helps control for student expectations of achievement based on their own current academic achievement. A variable describing how often a student's teacher talked to them about college was included to isolate teacher support, student educational aspirations, and confidence from each other, accounting for any teacher communication about future education.

Table 2: Confirmatory factor loadings

\begin{tabular}{|c|c|c|c|c|}
\hline \multirow[b]{2}{*}{ Item } & \multicolumn{2}{|c|}{$\begin{array}{l}\text { Teacher Emotional } \\
\text { Support }\end{array}$} & \multicolumn{2}{|c|}{$\begin{array}{l}\text { Teacher Academic } \\
\text { Support }\end{array}$} \\
\hline & Males & Females & Males & Females \\
\hline \multicolumn{5}{|l|}{ My Teachers: } \\
\hline Care about me & 0.805 & 0.797 & - & - \\
\hline Treat me fairly & 0.765 & 0.775 & - & - \\
\hline Appreciate me & 0.856 & 0.875 & - & - \\
\hline Really listen to what I have to say & 0.836 & 0.815 & - & - \\
\hline Tell me when I do a good job & 0.706 & 0.732 & - & - \\
\hline Give me encouragement & 0.813 & 0.812 & - & - \\
\hline Respect me & 0.728 & 0.740 & - & - \\
\hline \multicolumn{5}{|l|}{ Care about whether or not I come } \\
\hline to school & 0.697 & 0.741 & - & - \\
\hline Make it okay to ask questions & - & - & 0.737 & 0.759 \\
\hline $\begin{array}{l}\text { Help me solve problems by giving } \\
\text { me information }\end{array}$ & - & - & 0.824 & 0.847 \\
\hline Take time to help me learn to do & & & & \\
\hline something well & - & - & 0.876 & 0.865 \\
\hline Show me how to do things & - & - & 0.905 & 0.874 \\
\hline
\end{tabular}

Note. Standardized loadings are reported. All loadings are significant

Table 3: Regression model results of confidence by gender with and without moderation.

\begin{tabular}{|c|c|c|c|c|c|c|c|c|}
\hline \multirow[b]{3}{*}{ Variable } & \multicolumn{4}{|c|}{ Males $(n=245)$} & \multicolumn{4}{|c|}{ Females $(n=259)$} \\
\hline & \multicolumn{2}{|c|}{$\begin{array}{l}\text { Without } \\
\text { Moderation }\end{array}$} & \multicolumn{2}{|c|}{$\begin{array}{c}\text { With } \\
\text { Moderation }\end{array}$} & \multicolumn{2}{|c|}{$\begin{array}{l}\text { Without } \\
\text { Moderation }\end{array}$} & \multicolumn{2}{|c|}{$\begin{array}{l}\text { With } \\
\text { Moderation }\end{array}$} \\
\hline & Coef. & $(S E)$ & Coef. & $(S E)$ & Coef. & $(S E)$ & Coef. & $(S E)$ \\
\hline Educational Aspirations & 0.10 & $(0.18)$ & 0.14 & $(0.20)$ & -0.10 & $(0.18)$ & -0.14 & $(0.20)$ \\
\hline Academic teacher support & -0.20 & $(0.15)$ & $-1.18^{*}$ & $(0.54)$ & -0.09 & $(0.10)$ & $0.63 * *$ & $(0.22)$ \\
\hline Emotional teacher support & $0.33+$ & $(0.15)$ & $1.27 *$ & $(0.59)$ & 0.19 & $(0.19)$ & $-1.06 * *$ & $(0.42)$ \\
\hline $\begin{array}{l}\text { Moderation: Academic support } \\
\text { and aspirations }\end{array}$ & - & - & $0.53 *$ & $(0.25)$ & - & - & $-0.38 * *$ & $(0.13)$ \\
\hline $\begin{array}{l}\text { Moderation: Emotional support } \\
\text { and aspirations }\end{array}$ & - & - & $-0.48+$ & $(0.27)$ & - & - & $0.66^{* *}$ & $(0.24)$ \\
\hline Teacher discusses college & $-0.41 *$ & $(0.19)$ & $-0.45^{*}$ & $(0.19)$ & 0.21 & $(0.16)$ & 0.23 & $(0.17)$ \\
\hline Educational value & 0.12 & $(0.24)$ & 0.22 & $(0.26)$ & $0.57 *$ & $(0.27)$ & $0.69^{*}$ & $(0.29)$ \\
\hline Parental encouragement & $0.34+$ & $(0.20)$ & $0.39+$ & $(0.22)$ & $0.35+$ & $(0.20)$ & $0.37+$ & $(0.20)$ \\
\hline Family obligation & -0.05 & $(0.14)$ & 0.02 & $(0.15)$ & 0.01 & $(0.13)$ & 0.03 & $(0.14)$ \\
\hline Math grade & $0.53 * * *$ & $(0.15)$ & $0.61 * * *$ & $(0.17)$ & $0.26^{*}$ & $(0.13)$ & $0.29 *$ & $(0.13)$ \\
\hline English grade & $0.29 *$ & $(0.13)$ & $0.28 *$ & $(0.14)$ & $0.35^{* *}$ & $(0.12)$ & $0.38 * *$ & $(0.12)$ \\
\hline Age & -0.08 & $(0.12)$ & -0.03 & $(0.13)$ & $0.27 *$ & $(0.12)$ & $0.30 *$ & $(0.12)$ \\
\hline Parent education & 0.15 & $(0.14)$ & 0.17 & $(0.15)$ & -0.03 & $(0.13)$ & -0.03 & $(0.15)$ \\
\hline
\end{tabular}

Note: $+p<0.10 ;{ }^{*} p<0.05 ;{ }^{* *} p<0.01 ;{ }^{* * *} p<0.001$ 


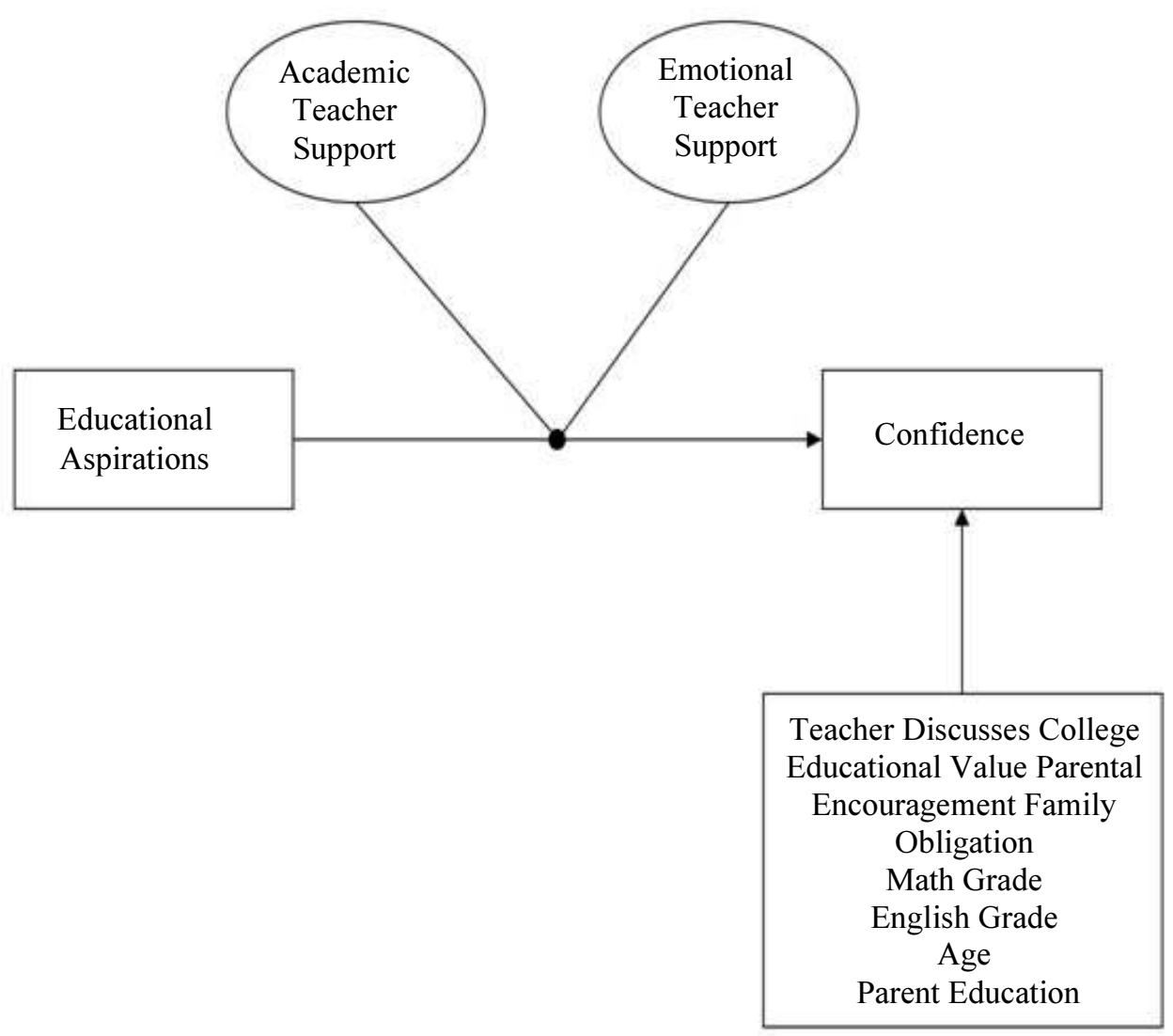

Fig. 1: Model diagram

This allows for the identification of teacher support as a separate entity that enables students to either believe in themselves and their ability to achieve their goals, or discourages that belief.

The unstandardized results of the regression model both with and without the moderation variables are presented in Table 3, and simple slope plots are presented in Fig. 2 and 3. There are dramatic differences in teacher support between the two genders, with the males and females inverted in the relationship between support moderated aspirations and confidence (see the simple slopes in Fig. 2 and 3). So while male students with high academic teacher support had a positive relationship between aspirations and confidence, female students with high academic teacher support had a negative relationship between aspirations and confidence. Likewise, while male students with low academic teacher support had a negative relationship between aspirations and confidence, female students with low academic teacher support had a positive relationship between aspirations and confidence.

The relationships are the opposite for emotional support: male students with high emotional teacher support had a negative relationship between aspirations and confidence, and female students had a positive relationship between the two. Male student with low emotional teacher support had a positive relationship between aspirations and confidence, while female students had a negative relationship between the two. Aspirations themselves are not significant for either males or females with or without moderation, but both academic and emotional teacher support are significant in the model with moderation, and all of the moderations are themselves at least marginally significant $(p<0.10)$. Males have a significant negative coefficient for academic teacher support $(b=-1.18, p<0.05)$, and a significant positive coefficient for academic teacher support's moderation of aspiration $(b=0.53, p<0.05)$. The coefficient difference between the models with and without moderation is significant, with male adolescents changing from -0.20 to $-1.18(p<0.05)$ in academic teacher support and from 0.33 to $1.27(p<0.05)$ in emotional teacher support, while female adolescents changed from 0.09 to $0.63(p<0.01)$ in academic teacher support and from 0.19 to $-1.06(p<0.01)$ in emotional teacher support. The $\mathrm{R}^{2}$ increased with the addition of the interaction variables. The $\mathrm{R}^{2}$ increased for male students from 0.27 to 0.36 and for female students from 0.20 to 0.32 . 


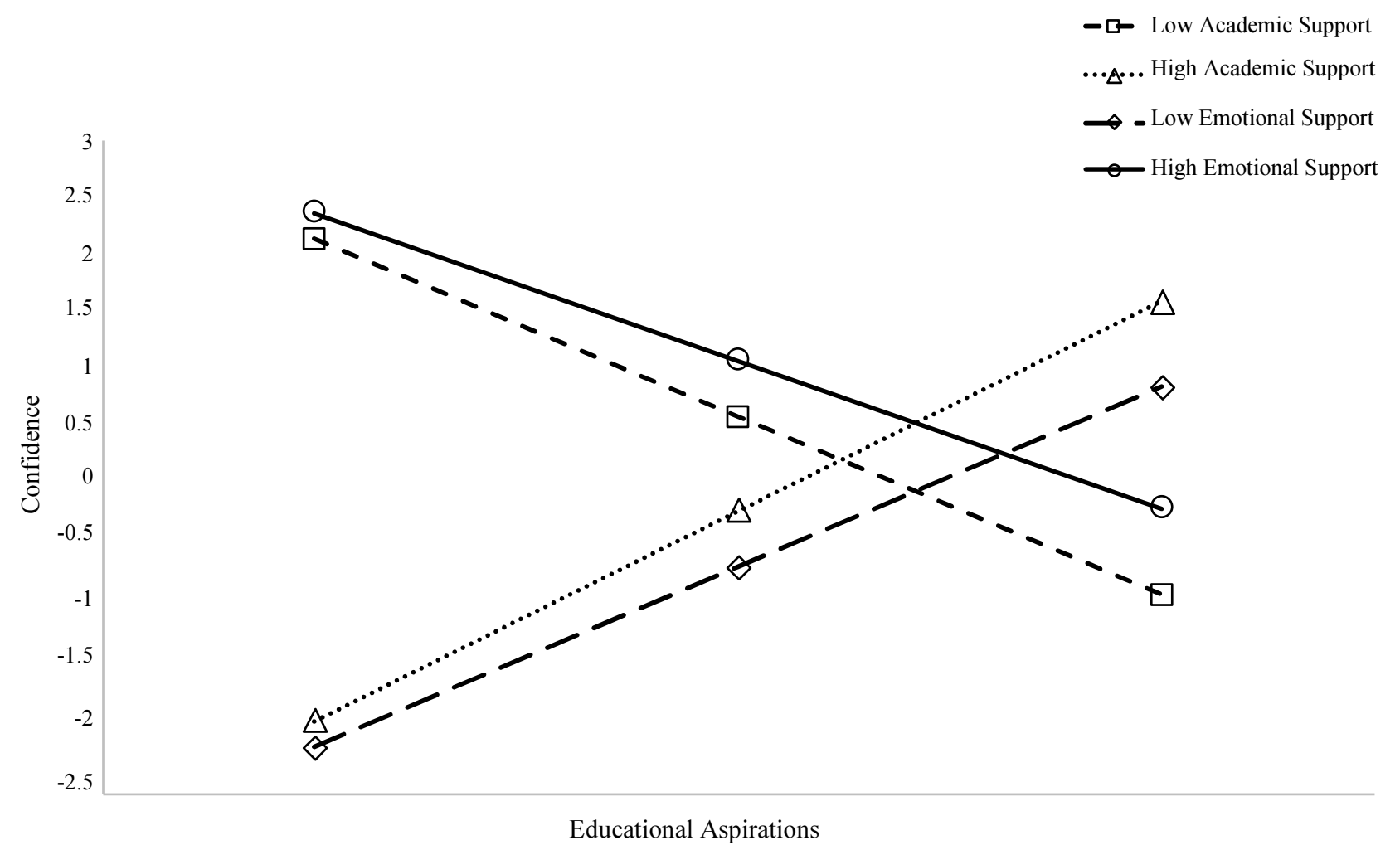

Fig. 2: Simple slopes plot of the academic teacher support moderation by gender for Latinx males

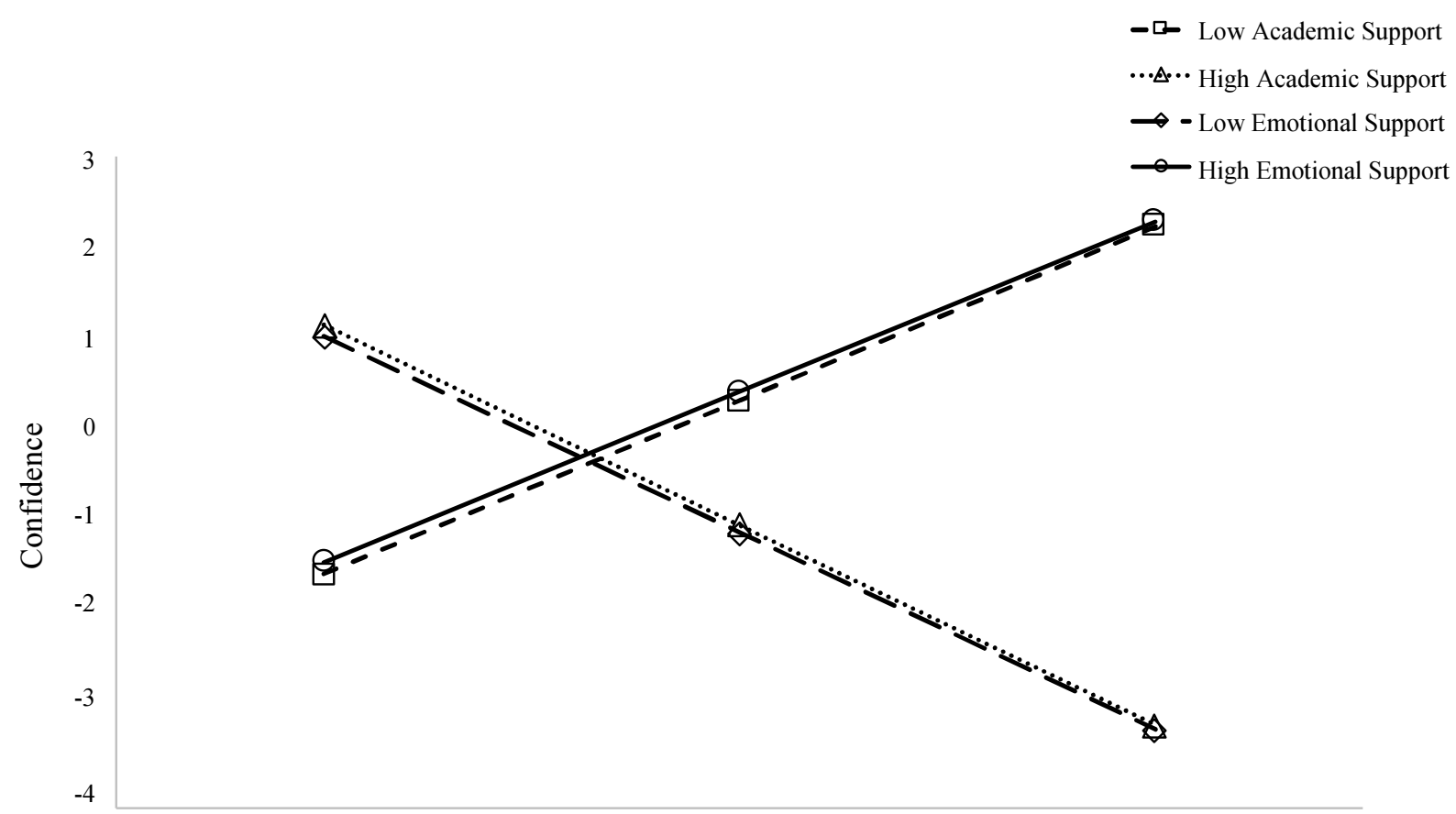

Educational Aspirations

Fig. 3: Simple slopes plot of the emotional teacher support moderation by gender for Latinx females 
Figure 2 presents the simple slopes for male students one standard deviation away from the mean of academic and emotional teacher support. Male students with high academic support increase in confidence as they increase in aspirations, while those with low academic support decrease in confidence as they increase in their aspirations. Male students also have a significant positive coefficient for emotional teacher support $(b=$ $1.27, p<0.05$ ), suggesting it is a significant predictor. However, there was only a marginally significant moderation of aspirations by teacher emotional support ( $b=-0.481, p<0.10$ ), implying teacher support may not be significant as a moderator. Regarding the covariates, the more male students' teachers discuss college with them, the lower their confidence $(b=-0.45, p<0.05)$. Parental encouragement is marginally significant in predicting confidence for male students ( $b=$ $0.39, p<0.10$ ), and academic achievement is strongly significant for prediction of confidence (Math: $b=$ $0.61, p<0.001$; English: $b=0.28, p<0.05)$. While it is unsurprising that higher academic achievement predicts students' higher confidence in their ability to achieve their educational goals, parental encouragement's ability to marginally predict confidence, especially within a teacher heavy model, suggests that parent encouragement can pick up some of the slack of low teacher support, or teacher support could pick up the slack of low parental encouragement. However, the coefficients of teacher support are much higher suggesting teacher support is a much stronger predictor.

Female students have the inverse relationship to teacher academic and emotional support compared to the males. Academic teacher support is significant and positive for females $(b<0.63, p<0.01)$, with a negative moderation effect $(b=-0.38, p<0.01)$. Review of the simple slopes (Fig. 3) reveals that females with low academic teacher support increase in confidence as their aspirations increase, while those with high academic support decrease in confidence as their aspirations increase. By contrast, females have a negative direct predictive coefficient for emotional teacher support ( $p=$ -1.06, $p<0.01$ ), and a positive moderation coefficient ( $b$ $=0.66, p<0.01)$. Females with high emotional support increase in confidence as they increase in their aspirations, while girls with low emotional support decrease in confidence as they increase in their aspirations. It is worth noting that the trend lines are practically identical yet inverted for high vs. low academic and emotional teacher support. The value females place on education is significantly related to confidence $(b=0.69, p<0.05)$, while the same is not true for males. Similar to male participants, females have marginal significance on parental encouragement, and academic achievement is significantly related to confidence (Math: $b=0.29, p<0.05$; English: $b=0.38$, $p<0.01)$. Age is also a significant predictor of confidence for girls $(b=0.30, p<0.05)$.

Math grade is a much stronger predictor of confidence for males than for females, and English grade is a slightly stronger predictor for females than for males. Teacher conversations about college is a predictor for males but not for females, and age is a predictor for females but not for males.

\section{Discussion}

Our findings indicate that students' aspirations for attending college seem to be greatly affected by the perceived amount of encouragement and support received from significant people in their lives, specifically their teachers. That is, the everyday interactions and communication with teachers are meaningful for high school students, suggesting that teachers can persuade students to perceive and visualize a potential to succeed in higher education. A major contribution of this paper is the finding that teacher support moderates the relationship between students' aspirations and confidence, and the type of teacher support that males and females perceive, alters this relationship between aspirations and confidence differently. Boys who perceive higher academic teacher support have greater confidence in their ability to achieve their aspirations, and girls who perceive high emotional teacher support have greater confidence in their ability to achieve their aspirations, showcasing the powerful role teachers can play in students' goals and academic development. Without teacher support, students may exhibit less confidence in their capabilities and undermine their potential to pursue more advanced degrees. Findings from this study also uncover that students may come into school with certain aspirations, encouraged by their family, friends, or previous teachers; yet, their most recent teacher support can make or break their belief in both themselves and their own ability to achieve their aspirations.

For Latinx students in particular, research shows that receiving emotional support and building relationships, especially from teachers, is critical for academic success (Valenzuela, 1999; Stanton-Salazar, 2001; Goyette and Conchas, 2002; Garcia-Reid et al., 2005; Conchas, 2006; Hudley and Daoud, 2008; Roshandel and Hudley, 2018). Building on this body of literature, this study suggests that communication and emotional support are essential in Latinx students' confidence about higher educational achievement. We found that students who reported high communication with and emotional support from teachers displayed significantly higher levels of confidence in their ability to accomplish their aspirations displaying high emotional support and providing 
meaningful interactions may be essential for teachers in promoting strong and advantageous educational trajectories for Latinx students.

This study also indicates gender differences exist with regards to how Latinx students perceive support from teachers, and the types of support that play a role in their future aspirations and their confidence surrounding these hopes. Without including this moderator or including it as another predictor instead of as a moderator, the importance of academic and emotional teacher support would be obscured, and the findings that students with varying levels of teacher support look completely different from each other would be overlooked. The large difference in teacher support coefficients between the regression models with and without moderation suggests the moderating effect of gender is vital to understanding the impact that teachers can have on students. This proposes that teacher support is experienced differently depending on students' hopes and motivations for themselves and their future, and ignoring this moderation in analyses would result in misinterpreting the considerable impact teachers can have on students' academic trajectories.

Further, without separating males and females and addressing them as unique groups for whom teacher support is inherently different, the inversion of the relationship males and females have between aspirations and confidence when moderated by teacher support (i.e. that academic teacher support is negatively related to confidence for males, and positively related to confidence for females, and vice versa for emotional teacher support) would be masked, resulting in an inability to understand what is happening in the data. This inverted relationship suggests that by testing males and females simultaneously, they would cancel each other out, resulting in no significant results in the relationship between teacher support and confidence for either gender, demonstrating the importance of testing for invariance and measuring the two groups separately. The inversion of the predictive, moderated relationship, not just between males and females but also between academic and emotional teacher support within group, also suggests that males and females have a different reaction to the type of support they receive, with academic support driving up males' confidence and driving down females' confidence and vice versa for emotional support. Our findings also convey that males and females receive different types of support when they have difficulty. Perhaps males receive more academic support when they are struggling and have high aspirations, whereas females with high aspirations receive more emotional support when struggling.

The increasing slopes for males (Fig. 2) and females (Fig. 3) in both the academic and emotional teacher support plots are close to parallel, while the decreasing slopes differ more between groups, with males having steeper slopes. This suggests the females who have confidence issues (i.e. report low levels of confidence) may suffer from them more than the males with confidence issues. However, while the variable was not significant for females, the coefficient was positive, again suggesting a differing relationship to teacher support for males and females. Math grades led to stronger confidence for males than for females. Similarly, Simpkins et al. (2015) found that female Latinx students had the lowest confidence in science motivation. This finding suggests an urgent need to further examine how to better support females' confidence surrounding STEM-related fields and how teachers may play a role in fostering young girls' confidence in this arena. Research suggests that adolescents who experienced more social support in their math classes reported higher social and academic adjustment and were more likely to attend college (Sakiz et al., 2012; BoutinMartinez et al., 2019).

The simple slopes also suggest that males with high academic teacher support increase in their confidence as they increase in their aspirations, while males with low academic support move in the opposite direction, decreasing in confidence as they increase in their aspirations, which suggests academic teacher support strongly moderates the relationship between aspirations and confidence. The marginal significance of the moderation coefficient for emotional support for males suggests that emotional support does not significantly moderate the relationship between aspirations and confidence. This indicates that emotional teacher support can weaken the relationship between aspirations and confidence for males, leveling out rather than steepening the slope. In other words, higher perceived emotional teacher support seems to decrease the strength of the relationship between male students' aspirations and their confidence in their ability to achieve those goals. However, this may be more indicative of the types of male students who seek out and receive emotional support from teachers, rather than of what the support itself does to the relationship.

This finding has important implications for males, specifically regarding the "vanishing male" in the educational pipeline (Sáenz and Ponjuan, 2009). Latinx males are considerably more likely to drop out of school and join the workforce than attend college. Although community college can serve as a safety net for many of these male students, they may be at risk for not transferring to a four-year university or dropping out altogether if confidence is not fostered. Far too often schools are eager to dismiss boys of color (Noguera, 2003; Saenz and Ponjuan, 2011; Noguera and Hurtado, 2012; Howard, 2014; Huerta et al., 2018). The extent to which confidence plays a role in males' college success 
is an important research question that future studies should examine. Without perceived teacher support, students may lose faith in their capabilities, which in turn may affect their motivation to fully explore their college options-this problem is especially relevant for male students. The argument has also been made that negative media images and role models for young men encourage risky behavior while devaluing academic attainment (Reynolds and Pemberton, 2001; Blackhurst and Auger, 2008).

Specifically, the moderation of aspirations, or the interaction between teacher support factors and those aspirations, showed a dramatic difference in support between the two genders, suggesting that boys who receive less academic support from teachers have higher confidence of achieving their aspirations. This finding may support an idea found in literature on the miseducation and colonization of students of color, which argues that less socialization from educators might serve as a protective factor by allowing these students to find guidance from more caring, relevant individuals in their communities who might have higher expectations and be more culturally responsive (Woodson, 1933; Valenzuela, 2010; Stanton-Salazar, 2011). Similarly, teachers who attempt to support Latinx males in their college pursuits may cause more harm than good by inadvertently discouraging them from attending. Future research should examine how teachers communicate with male about their future academic endeavors. Given that Latinx males are most likely to enroll in community college and the least likely to transfer compared to other ethnic groups, (Sáenz and Ponjuan, 2011; Simmons, 2012) there is reason to further investigate how these conversations may shape the future trajectories of Latinx males.

Age was also included with the understanding that as students get closer to graduation, their confidence that they can achieve their goals may change, along with their understanding of the feasibility of those goals. Interestingly, as females got older, their confidence that they can achieve their goals increased, yet for males, there was no significant relationship with age and confidence, however there was a trending negative relationship, suggesting that as Latinx boys get older, they potentially lose confidence in their future aspirations.

The finding that females with low emotional teacher support have less confidence as they increase in aspirations suggests females may need more support from a socio-emotional standpoint to feel successful and confident in their abilities, while that socio-emotional support makes males feel less confident. The inverse is true for academic support: when females receive more academic support, they feel less confident relative to their aspirations, whereas males with more academic support feel more confident relative to their aspirations. This illustrates several potential explanations, including that teachers may offer different types of support to students of different genders when they are struggling or doing well. Perhaps teachers preconceptions of gender, particularly racialized gender, may lead to differential treatment.

\section{Limitations}

As there are only two latent variables, estimation of any higher order factor was not possible, despite the high correlation between them; conceptually, the two factors were considered distinct, and thus not combined. Furthermore, the study utilized a relatively small sample size, influencing the significance of the results. A larger increase in participants may produce more powerful findings. This study also took place within one high school; therefore, data collection at different school sites with varying urbanicities is recommended to capture nuances between groups.

\section{Implications and Future Research}

Future work should closer examine the frequencies and types of conversations students have with their teachers about their post-high school plans to identify effective ways for teachers to foster the development of confidence within their students, especially as they consider college. Together with the current study, we see the power verbal persuasion and communication from teachers that can make a difference in how students perceive their futures. Our findings regarding the relationship between teacher support and male students raises questions about the content of and reasons for these conversations; do teachers speak with male students about college in order to temper their expectations and offer alternative options?

Teachers have the potential to contribute to students' level of confidence that they can achieve their academic goals, and in turn, counter the socially constructed psychological barrier of confidence (Bowen et al., 2013). One mechanism for nurturing their potential may be engaging in pedagogical strategies of emotional support by creating genuine emotional connections with students in an attempt to help shape their future aspirations. School leaders can benefit from trainings around building connections, relationships, and culturally relevant pedagogy with all of their students (Valenzuela, 2016).

\section{Conclusion}

This study suggests that teacher support plays an important role in Latinx students' higher education aspirations and confidence. Emotional connections between teacher and students may boost levels of confidence for both males and females, regardless of whether they aspire to attain a community college degree, a BA degree or a graduate school degree. 
Teachers may hold the key to helping Latinx students reach their full potential; given that self-confidence can be thought of as one of the most influential motivators (Bandura, 1997). Therefore, while negative verbal persuasion or lack of any verbal communication can contribute to students' doubts that they can achieve their goals, supportive communication from teachers, as well as academic help, can benefit students' academic identities and trajectories, which may lead qualified Latinx students to pursue higher levels of education at more selective institutions.

\section{References}

Alfaro, E.C., A.J. Umaña $\square$ Taylor and M.Y. Bámaca. 2006. The influence of academic support on Latino adolescents' academic motivation. Family Relations, 55: 279-291.

DOI: $10.1111 / \mathrm{j} .1741-3729.2006 .00402 . x$

Bandura, A., 1997. Self-efficacy: The Exercise of Control. Freeman, New York. ISBN: 978-0716728504.

Bentler, P.M., 1990. Comparative fit indexes in structural models. Psychological Bulletin, 107: 238246. DOI: 10.1037/0033-2909.107.2.238

Blackhurst, A. and R. Auger, 2008. Precursors to the gender gap in college enrollment: Children's aspirations and expectations for their futures. Professional School Counseling, 11: 149-158. DOI: 10.5330/PSC.n.2010-11.149

Bohon, S.A., M.K. Johnson and B.K. Gorman, 2006. College aspirations and expectations among Latino adolescents in the United States. Social Problems, 53: 207-225. DOI:10.1525/sp.2006.53.2.207

Boutin-Martinez, A., R. Mireles-Rios, K. NylundGibson and O. Simon, 2019. Exploring Resilience in Latina/o academic outcomes: A Latent Class Approach. J. Edu. Students Placed Risk (JESPAR), 24:174191.DOI:10.1080/10824669.2019.1594817

Bowen, N.K., K.M. Wegmann and K.C. Webber, 2013. Enhancing a brief writing intervention to combat stereotype threat among middle-school students. J. Educ. Psychol., 105: 427-435.

DOI: $10.1037 / \mathrm{a} 0031177$

Boxer, P., S.E. Goldstein, T. DeLorenzo, S. Savoy and I. Mercado, 2011. Educational aspiration-expectation discrepancies: Relation to socioeconomic and academic risk-related factors. J. Adolescence, 34: 609-617. DOI: 10.1016/j.adolescence.2010.10.002.

Brewster, A.B. and G.L. Bowen. 2004. Teacher support and the school engagement of Latino middle and high school students at risk of school failure. Child Adolescent Soc. Work J., 21: 47-67.

DOI: 10.1023/B:CASW .0000012348.83939.6b.
Brown, T.A., 2006. Confirmatory factor analysis for applied research. New York: Guilford.

Cheung, G.W. and R.B., Rensvold, 2002. Evaluating goodness-of-fit indexes for testing measurement invariance. Structural Equation Modeling, 9: 233255. DOI: $10.1207 /$ S15328007SEM0902_5

Conchas, G.Q. and J.D. Vigil, 2010. Multiple marginality and urban education: Community and school socialization among low-income Mexicandescent youth. J. Educ. Students Placed Risk, 15: 51-65. DOI: 10.1080/10824661003634963

Conchas, G.Q., 2006. The Color of Success: Race and High-Achieving Urban Youth. Teachers College Press, New York. ISBN-10: 0807746606.

Contreras, F., 2011. Strengthening the bridge to higher education for academically promising underrepresented students. J. Adv. Academics, 22: 500-526. DOI: 10.1177/1932202X1102200306

Costello, A.B. and J.W. Osborne, 2005. Best practices in exploratory factor analysis: Four recommendations for getting the most from your analysis. Practical Assessment Res. Eva., 10: 1-9.

Croninger, R.G. and V. E. Lee, 2001. Social capital and dropping out of high school: Benefits to at-risk students of teachers' support and guidance. Teach. College Record, 103: 548-581.

DOI: $10.1111 / 0161-4681.00127$

Davis, H.A., 2013. Teacher-Student Relationships. In: International Guide to Student Achievement, Hattie, J. and E.M. Anderman (Eds.), Routledge, New York, pp: 101-103. ISBN-10: 0415879019

Fabrigar, L.R., D.T. Wegener, R.C. MacCallum and E.J. Strahan, 1999. Evaluating the use of exploratory factor analysis in psychological research. Psychol. Methods, 4: 272-299.

DOI: $10.1037 / / 1082-989 X .4 .3 .272$

Flores-Gonzalez, N., 2002. School Kids/Street Kids: Identity Development in Latino Students. Teachers College Press, New York. ISBN-10: 0807742236

Fry, R., 2009. College Enrollment Hits All-Time High, Fueled by Community College Surge. Pew Res. Center Publications.

Furrer, C. and E. Skinner, 2003. Sense of relatedness as a factor in children's academic engagement and performance. J. Educ. Psychol., 95: 148-162. DOI: 10.1037/0022-0663.95.1.148

Gándara, P.C. and F. Contreras, 2009. The Latino Education Crisis: The Consequences of Failed Social Policies. Harvard University Press, Massachusetts. ISBN-10: 9780674047051

Garcia, G. A. (2018). What does it mean to be Latinxserving? Testing the utility of the typology of HSI organizational identities. Association Mexican Am. Educators J., 11: 109-138.

DOI: 10.24974 amae.11.3.363 
Garcia-Reid, P., R.J. Reid and N.A. Peterson, 2005. School engagement among Latino youth in an urban middle school context: Valuing the role of social support. Educ. Urban Soc., 37: 257-275. DOI: $10.1177 / 0013124505275534$

Gehlbach, H., M.E. Brinkworth, A.M. King, L.M. Hsu and J. McIntyre et al., 2016. Creating birds of similar feathers: Leveraging similarity to improve teacher-student relationships and academic achievement. J. Educ. Psychol., 108: 342-352. DOI: $10.1037 /$ edu0000042

Goodenow, C., 1993. Classroom belonging among early adolescent students' relationships to motivation and achievement. J. Early Adolescence, 13: 21-43. DOI: $10.1177 / 0272431693013001002$

Goyette, K.A. and G.Q. Conchas, 2002. Family and nonfamily roots of social capital among vietnamese and mexican american children. In: Schooling and Social Capital in Diverse Cultures, B. Fuller and E. Hannum (Eds.), Elsevier Science, Boston, MA, pp: 41-72. DOI: $10.1177 / 1474904116682248$

Gregory, A. and R.S. Weinstein, 2004. Connection and regulation at home and in school predicting growth in achievement for adolescents. J. Adolescent Res., 19: 405-427. DOI: 10.1177/0743558403258859

Gutman, L.M. and R. Akerman, 2008. Determinants of aspirations. Centre Res. Wider Benefits Learning, Institute Education, London. ISBN-10: 978-0-9552810-7-5

Halx, M.D. and M. Ortiz, 2011. Voices of Latino male high school students on their disconnect with education: Perspectives of drop-outs and those on the brink. Latino Studies, 9: 416-438. DOI: $10.1057 / 1$ st.2011.49

Hossler, D. and K.S. Gallagher, 1987. Studying student college choice: A three-phase model and the implications for policy-makers. College University, 62: 207-221.

$\mathrm{Hu}$, L. and P.M. Bentler, 1999. Cutoff criteria for fit indexes in covariance structure analysis: Conventional criteria versus new alternatives. Structural Equation Modeling, 6: 1-55. DOI: $10.1080 / 10705519909540118$

Hudley, C. and A.M. Daoud, 2008. Cultures in Contrast: Understanding the Influence of School Culture on Student Engagement. In: Academic Motivation and the Culture of School in Childhood and Adolescence, Hudley, C. and A.E. Gottfried (Eds.), Oxford University Press, New York, pp: 187-220. ISBN: 9780195326819

Huerta, A.H., 2015. I didn't want my life to be like that: Gangs, college, or the military for Latino male high school students. J. Latino/Latin Am. Stud., 7: 119132. DOI: 10.18085/1549-9502-7.2.119
Huerta, A.H., P.M. McDonough and W.R. Allen, 2018. You can go to college: Employing a developmental perspective to examine how young men of color construct a college-going identity. The Urban Rev., 50: 713-734. DOI: $10.1007 / \mathrm{s} 11256-018-0466-9$

Ibañez, G.E., G.P. Kuperminc, G. Jurkovic and J. Perilla, 2004. Cultural attributions and adaptations linked to achievement motivation among Latino adolescents. J. Youth Adolescence, 33: 559-568. DOI: $10.1023 / \mathrm{B}: J O Y O .0000048069 .22681 .2 \mathrm{c}$

Kao, G. and M. Tienda, 1998. Educational aspirations of minority youth. Am. J. Edu., 106: 349-384. DOI: $10.1086 / 444188$

Katz, S.R., 1999. Teaching in tensions: Latino immigrant youth, their teachers, and the structures of schooling. Teachers College Record, 100: 809-840. DOI: $10.1111 / 0161-4681.00017$

Klasik, D., 2012. The college application gauntlet: A systematic analysis of the steps to four-year college enrollment. Res. Higher Edu., 53: 506-549. DOI: $10.1007 / \mathrm{s} 11162-011-9242-3$

Krogstad, J.M., 2016. Five Facts About Latinos and Education. Pew Res. Center.

Kuperminc, G.P., A.J. Darnell and A. Alvarez-Jimenez, 2008. Parent involvement in the academic adjustment of Latino middle and high school youth: Teacher expectations and school belonging as mediators. J. Adolescence, 31: 469-483.

DOI: 10.1016/j.adolescence.2007.09.003

Loya, K.I., J. Hwang and L. Oseguera, 2015. Latina/o students' college destinations: Gender, generational status, and college sector selectivity. In Higher education access and choice for Latino students: Critical findings and theoretical perspectives. Taylor and Francis Inc.

Magnuson, K., G.J. Duncan and A. Kalil, 2006. The Contribution of Middle Childhood Contexts to Adolescent Achievement and Behavior. In: Developmental Contexts in Middle Childhood: Bridges to Adolescence and Adulthood, Huston, A.C. and M.N. Ripke (Eds.), Cambridge University Press, Cambridge, UK, pp: 150-172. ISBN: 9780511499760

Malecki, C.K. and M.K. Demaray, 2002. Measuring perceived social support: Development of the Child and Adolescent Social Support Scale (CASSS). Psychol. Schools, 39: 1-18.

DOI: $10.1002 /$ pits. 10004

Malecki, C.K. and M.K. Demaray, 2003. What type of support do they need? Investigating student adjustment as related to emotional, informational, appraisal, and instrumental support. School Psychol. Q., 18: 231-252. DOI: 10.1521/scpq.18.3.231.22576 
Marsh, H.W., K.T. Hau, Z. Wen, B. Nagengast and A.J.S. Morin, 2013. Moderation. In: Oxford Library of Psychology, T.D. Little (Ed.), The Oxford Handbook of Quantitative Methods: Statistical Analysis. pp: 361-386. New York, US: Oxford University Press.

Martinez, E. and M. Castellanos, 2018. Catching them early: An examination of Chicano/Latino middle school boys early career aspirations. Urban Rev., 50: 378-401. DOI: 10.1007/s11256-017-0438-5

McGlynn, A.P., 2015. Black males and Latinos: Aspiration, achievement, and equity. Educ. Digest, 80: 57-60.

Meade, M.O., D.J. Cook, G.H. Guyatt, A.S. Slutsky and Y.M. Arabi et al., 2008. Ventilation strategy using low tidal volumes, recruitment maneuvers, and high positive end-expiratory pressure for acute lung injury and acute respiratory distress syndrome: A randomized controlled trial. Jama, 299: 637-645.

Mireles-Rios, R. and L.F. Romo, 2010a. Maternal and teacher interaction and student engagement in math and reading among Mexican American girls from a rural community. Hispanic J. Behavioral Sci., 20: 1-14. DOI: 10.1177/0739986310374020.

Mireles-Rios, R. and L.F. Romo, 2010b. Latina daughters childbearing attitudes: The role of maternal expectations and education communication. Develop. Psychol., 50: 1553-1563. DOI: 10.1037/a0035471

Muthén, B.O., 1984. A general structural equation model with dichotomous, ordered categorical, and continuous latent variable indicators. Psychometrika, 49: 115-132.

DOI: $10.1007 / \mathrm{BF} 02294210$

Muthén, B.O., S.H. Du, D. Spisic and S.H.C. du Toit, 1997. Robust inference using weighted least squares and quadratic estimating equations in latent variable modeling with categorical and continuous outcomes. Unpublished Technical Report.

Muthén, L.K. and Muthén, B.O. (1998-2017). Mplus User's Guide. Eighth Edition. Los Angeles, CA: Muthén \& Muthén

Muthén, L.K. and B.O. Muthén, 2017. Mplus Statistical Analysis with Latent Variables: User's Guide. 8th Educ. Muthén and Muthén, California. ISBN-10: 0982998325

NCES, 2016. The Condition of Education 2016: Racial/Ethnic Enrollment in Public Schools (NCES 2016-144). National Center for Educational Statistics.

Niehaus, K., M.J. Irvin and S. Rogelberg, 2016. School connectedness and valuing as predictors of high school completion and postsecondary attendance among Latino youth. Contemporary Educ. Psychol., 44: 54-67. DOI: 10.1016/j.cedpsych.2016.02.003
Noguera, P.A. and A. Hurtado, 2012. Invisible No More: The Status and Experience of Latino Males from multidisciplinary perspectives. In: Invisible No More: Understanding the Disenfranchisement of Latino Men and Boys, Noguera, P.A., A. Hurtado and E. Fergus, (Eds.), Routledge, New York, pp: 116. ISBN-10: 0415877792

Noguera, P.A., 2003. Schools, prisons, and social implications of punishme Practice, 42: 341-350. DOI: $10.1207 / \mathrm{s} 15430421$ tip4204_12

Nuñez, A.M. and D. Kim, 2012. Building a multicontextual model of Latino college enrollment: Student, school, and state-level effects. Rev. Higher Edu., 35: 237-263. DOI: 10.1353/rhe.2012.0004

Reynolds, J.R. and J. Pemberton, 2001. Rising college expectations among youth in the United States: A comparison of the 1979 and 1997 NLSY. J. Human Res. 36: 703-726. DOI: 10.2307/3069639

Rios, V.M., 2011. Punished: Policing the Lives of Black and Latino Boys. NYU Press, New York. ISBN-10: 0814776388

Rios, V.M., 2017. Human Targets: Schools, Police and the Criminalization of Latino Youth. University of Chicago Press, Illinois. ISBN: 022609099X

Roshandel, S. and C. Hudley, 2018. Role of teachers in influencing the development of adolescents possible selves. Learn. Environ. Res., 21: 211-228. DOI: 10.1007/s10984-017-9247-8

Sáenz, V.B. and L. Ponjuan, 2009. The vanishing Latino male in higher education. J. Hispanic Higher Edu., 8: 54-89. DOI: 10.1177/1538192708326995

Sáenz, V.B. and L. Ponjuan, 2011. Men of Color: Ensuring the Academic Success of Latino Males in Higher Education. Institute Higher Educ. Policy Washington, DC.

Sakiz, G., S.J. Pape and A.W. Hoy, 2012. Does perceived teacher affective support matter for middle school students in mathematics classrooms. J. School Psychol., 50: 235-255. DOI: $10.1016 /$ j.jsp.2011.10.005

Sánchez, B., Y. Colón and P. Esparza, 2005. The role of sense of school belonging and gender in the academic adjustment of Latino adolescents. J. Youth Adolescence, 34: 619-628. DOI: $10.1007 / \mathrm{s} 10964-005-8950-4$

Sass, D.A., 2011. Testing measurement invariance and comparing latent factor means within a confirmatory factor analysis framework. J. Psychoeducational Assessment, 29: 347-363. DOI: $10.1177 / 0734282911406661$

Simmons, J., 2012. Shedding light on an education crisis. The Hispanic Outlook Higher Educ., 22: 31. 
Simpkins, S.D., C.D. Price and K. Garcia, 2015. Parental support and high school students' motivation in biology, chemistry and physics: Understanding differences among Latino and Caucasian boys and girls. J. Res. Sci. Teach., 52: 1386-1407. DOI: $10.1002 /$ tea.21246

Stanton-Salazar, R.D., 2001. Manufacturing Hope and Despair: The School and Kin Support Networks of US-Mexican Youth. Teachers College Press, New York. ISBN-10: 0807741086

Stanton-Salazar, R.D., 2011. A social capital framework for the study of institutional agents and their role in the empowerment of low-status students and youth. Youth Soc., 43: 1066-1109. DOI: $10.1177 / 0044118 X 10382877$

Taggart, A. and J. Paschal, 2017. The influence of equitable treatment on Latina/o high school students' college aspirations. J. Latinos Educ. DOI: $10.1080 / 15348431.2017 .1390465$

Tellez, K. and M. Estep, 1997. Latino youth gangs and the meaning of school. High School J., 81: 69-81.

Valenzuela, A., 2010. Subtractive schooling: us-mexican youth and the politics of caring. State University of New York Press, New York. ISBN-10: 0791443221

Valenzuela, A., 2016. Growing critically conscious teachers: a social justice curriculum for educators of latino/a Youth. Teachers College Press, New York. ISBN: 0807756830

Vandenberg, R.J. and C.E. Lance, 2000. A review and synthesis of the measurement invariance literature: Suggestions, practices, and recommendations for organizational research. Organ. Res. Methods, 3: 4-69. DOI: $10.1177 / 109442810031002$

Walkey, F.H., J. McClure, L.H. Meyer and K.F. Weir, 2013. Low expectations equal no expectations: Aspirations, motivation, and achievement in secondary school. Contemporary Edu. Psychol., 38: 306-315. DOI: 10.1016/j.cedpsych.2013.06.004

Wei-Cheng, M. and L.H. Bikos, 2000. Educational and vocational aspirations of minority and female students: A longitudinal study. J. Counseling Develop., 78: 186-194. DOI: $10.1002 / \mathrm{j} .1556-6676.2000 . t b 02577 . x$

Wentzel, K.R., 1997. Student motivation in middle school: The role of perceived pedagogical caring. J. Educ. Psychol., 89: 411-419.

DOI: $10.1037 / 0022-0663.89 .3 .411$
Wentzel, K.R., 1998. Social relationships and motivation in middle school: The role of parents, teachers, and peers. J. Educ. Psychol., 90: 202-209.

DOI: $10.1037 / 0022-0663.90 .2 .202$

Wentzel, K.R., S. Russell and S. Baker, 2016. Emotional support and expcectations from parents, eachers and peers predict adolescent competence at school. J. Educ. Psychol., 108: 242-255. DOI: $10.1037 /$ edu0000049

Wilson, P.M. and J.R. Wilson, 1992. Environmental influences on adolescent educational aspirations: A logistic transform model. Youth Soc., 24: 52-70. DOI: $10.1177 / 0044118$ X92024001003

Witenko, V., R. Mireles-Rios and V.M. Rios, 2017. Networks of encouragement: who's encouraging latina/o students and white students to enroll in honors and Advanced-Placement (ap) courses. J. Latinos Educ., 16: 176-191.

Woodson, C.G., 1933. The Mis-Education of the Negro. Associated Publishers, Washington, D.C. ISBN-10: 1680920685.

Woolley, M.E. and A. Grogan $\square$ Kaylor, 2006. Protective family factors in the context of neighborhood: Promoting positive school outcomes. Family Relations, 55: 93-104. DOI: $10.1111 /$ j.1741-3729.2006.00359

Yu, C.Y., 2002. Evaluating cutoff criteria of model fit indices for latent variable models with binary and continuous outcomes. Unpublished dissertation in partial fulfillment of the requirements for the degree of Doctor of Philosophy, University of California, Los Angeles, California, United States.

Zalaquett, C.P. and A.D. Lopez, 2006. Learning from the stories of successful undergraduate Latina/Latino students: The importance of mentoring. Mentoring Tutoring, 14: 337-353.

DOI: $10.1080 / 13611260600635563$

Zarate, M.E. and R. Burciaga, 2010. Latinos and college access: Trends and future directions. J. College Admission, 209: 24-29.

Zarate, M.E. and R. Gallimore, 2005. Gender differences in factors leading to college enrollment: A longitudinal analysis of Latina and Latino students. Harvard Educ. Rev., 75: 383-408.

Zhang, Y., E. Haddad, B. Torres and C. Chen, 2011. The reciprocal relationships among parents expectations, adolescents' expectations and adolescents achievement: A two-wave longitudinal analysis -8. 